\title{
Denise Shorey
}

\section{the way I see it}

\section{It takes two \\ Negotiating the dance of management}

M

any years ago, when I took ballroom dancing

lessons, the instructor told us that the rst thing to remember was that the man leads, the woman follows. The feminist in me reared up and protested: What!? Why should he always have the fun? How come women can t be in charge? That makes no sense!

Ah, but it does.

It takes a lot of skill to be able to follow well The ability to anticipate your partner s needs, read your partners any partners body language, remain attuned to subtle nuances and differences among partners, support your partner by placing your feet just right. . . ah, these are skills that require as much training as the other. Remember what Ginger did? Everything that Fred did. . . only backwards, and in high heels.

In this sense, dancing (leading and following) is somewhat akin to managing; and it s not always easy.

I ve always assumed that part of my job was to make the life of my supervisor easier. That doesn $t$ mean that I need to brown-nose that person, or make myself a doormat. No, it means that I need to be aware of what that person is facing, what s coming down the pike, and what he or she needs to do to sidestep any possible collision. A good partner remembers what the room looks like, keeps in mind the swirling con gurations, and is able to adjust, sometimes with no notice, to a quick change of direction.

Does that mean that you always have to agree with the steps that your partner decides to take? What if you really like the direction you ve just taken, perhaps a straight-line foxtrot? For no reason at all, your partner decides to change direction, do a 90-degree turn; and you realize that there was no collision imminent? Do you scold, pout, insist on going back the way it was before?

It $s$ too late now for that, sorry.

To stop at that point and argue would disrupt the ow of activity in the room. Later, there will be time for discussion. Right now, just move along, please.

Managers appreciate good supervisees. Nobody likes yes-people they d be the rst to lead you, or let you go, over the edge of the cliff. But what makes a good supervisee? Shouldn t you, as a manager, seek out and support people who know their own minds, aren $t$ afraid to speak up, and who will help to prevent a (maybe your) dictatorship?

Well, yes. But an excellent supervisee, like a fantastic partner, knows when to relax, when to counter, and when to go with the ow. Communicate. Not your ow: the ow of whatever s best for the department or the institution. This is someone who genuinely wants to see you succeed and be the star of the show. In managerial terms, the critical idea here is support the realization that a supervisee is important to the manager s success. The best supervisees are those who understand that managers make course adjustments, sometimes go off track, and sometimes lose their concentration. If you feel the pressure of your partner s hand lighten, it $s$ time to help to keep things going.

Now, we re not talking about leadership here, though of course for every follower there must be a leader. I may not like my supervisor s vision, may not feel that he or she even has any leadership skills I may not even trust him or her. And if my options are constrained, I will have no choice but to remain in the organization, though I might try to lead from behind.

But in the organizational dance, where eyes judge my supervisor s management skills. . I have an important no, a critical part to play. You can $t$ dance solo and you can t manage solo.

It takes two. $\pi$

Denise Shorey is associate director for user services at the University of Notre Dame Hesburgh LIbraries, e-mail: dshorey@nd.edu

o 2009 Denise Shorey 